\title{
Partial Edentulism based on Kennedy's Classification: An Epidemiological Study
}

\author{
${ }^{1} \mathrm{M}$ Bharathi, ${ }^{2}$ Kethi Reddy Mahesh Babu, ${ }^{3}$ Giridhar Reddy, ${ }^{4}$ Naveen Gupta, ${ }^{5}$ Abhinav Misuriya, ${ }^{6} \mathrm{~V}$ Vinod
}

\section{ABSTRACT}

Background: The aim of this study was to determine the incidence of different Kennedy's classes of partial edentulism during 18 months period.

Materials and methods: Patients were clinically examined for various Kennedy's classes of partial edentulism in the outpatient department (OPD), prosthodontics, GPRDCH, Kurnool (Andhra Pradesh)

Results: Of the total 1,420 OPD patients, Kennedy's class III was the most frequent classification encountered $(62 \%)$ and followed by Kennedy's class I (18\%), class II (11\%), and class IV $(9 \%)$ in decreasing order.

Conclusion: The patients with various Kennedy's classes of partial edentulism can be offered various treatment modalities like removable cast partial dentures, fixed partial dentures, over dentures and implant supported dentures. This study can be crucial for screening the population for incidence of tooth loss as a factor of gender and age.

Clinical significance: Tooth loss appears to have an important role in the loss of esthetics and mastication. Study of incidence of various classes of partial edentulism provides clinically useful information for dental training and continuing education.

Keywords: Epidemiology, Kennedy's classification, Partial edentulism.

How to cite this article: Bharathi M, Babu KRM, Reddy G, Gupta N, Misuriya A, Vinod V. Partial Edentulism based on Kennedy's Classification: An Epidemiological Study. J Contemp Dent Pract 2014;15(2):229-231.

\footnotetext{
${ }^{1}$ Professor, ${ }^{2-5}$ Reader, ${ }^{6}$ Lecturer

${ }^{1,3}$ Department of Prosthodontics, G Pulla Reddy Dental College, Kurnool, Andhra Pradesh, India

${ }^{2}$ Department of Prosthodontics, Meghna Institute of Dental Sciences, Nizamabad, Andhra Pradesh, India

${ }^{4}$ Department of Prosthodontics, Institute of Dental Education and Advanced Studies, Etawah Road, Gwalior, Madhya Pradesh, India

${ }^{5}$ Department of Endodontics, Vananchal Dental College and Hospital, Garhwa, Jharkhand, India

${ }^{6}$ Department of Prosthodontics, Oxford Dental College and Hospital, Bengaluru, Karnataka, India
}

Corresponding Author: V Vinod, Lecturer, Department of Prosthodontics, Oxford Dental College and Hospital, Bengaluru Karnataka, India, e-mail: drvinod@mail.com

\section{Source of support: Nil}

Conflict of interest: None declared

\section{INTRODUCTION}

Despite dramatic improvements in tooth retention around the world, a substantial portion of population loses natural teeth and is a candidate for prosthodontic rehabilitation. Partially edentulous patients exhibit a wide range of physical variations and health conditions. ${ }^{1}$ Teeth loss effects speech, mastication and may result in poor esthetics which in turn affect the quality of life.

Several studies of trends in removable prosthodontic service showed that the number of complete dentures is declining; number of partial dentures is increasing. This reflects the changes in dental treatments provided which encourage the preservation of natural teeth and the decrease in the number of cases require complete dentures. ${ }^{2}$ The patterns of tooth loss have been evaluated in many selected populations in different countries and the frequency of partial edentulousness seems to vary widely between different countries.

The prevalence and patterns of tooth loss have been studied to a certain extent in other countries but a few studies have been carried out in our country. A simple estimation of the proportion of partially edentulous persons is a rough indication of the prevalence of dental diseases and the success or failure of dental care. This forms a background for the assessment of treatment needs. ${ }^{3}$ The need for classification of partially edentulous arches is to communicate about condition of oral cavity in which missing teeth are to be replaced ${ }^{4}$ and also partial denture designing. ${ }^{5}$ A classification of partially edentulous arches not only helps to identify potential combinations of teeth to edentulous ridges, thus facilitating communication,

Table 1: Age and gender distribution of the sample

\begin{tabular}{llll}
\hline Age group & Female & Male & Total $n(\%)$ \\
\hline $15-20$ yrs & 37 & 33 & $70(5)$ \\
$21-30$ yrs & 94 & 95 & $189(13)$ \\
$31-40$ yrs & 170 & 183 & $353(25)$ \\
$41-50$ yrs & 211 & 212 & $423(30)$ \\
$51-60$ yrs & 130 & 131 & $261(18)$ \\
$61-70$ yrs & 33 & 74 & $107(8)$ \\
$71-80$ yrs & 0 & 17 & $17(1)$ \\
\hline Total & 675 & 745 & $1420(100)$ \\
\hline
\end{tabular}


Table 2: Frequency of different classes of partial edentulism according to Kennedy's classification

\begin{tabular}{llllll}
\hline Arch & Class I $n(\%)$ & Class II $n(\%)$ & Class III $n(\%)$ & Class IV $n(\%)$ & Total $n(\%)$ \\
\hline Maxilla & $145(16)$ & $85(9)$ & $592(66)$ & $902(100)$ & $79)$ \\
Mandible & $163(20)$ & $103(12)$ & $495(59)$ & $77(9)$ & $838(100)$ \\
\hline
\end{tabular}

Table 3: Frequency of different classes of partial edentulism according to age and gender of patients (number $=1,740)$.

\begin{tabular}{|c|c|c|c|c|c|}
\hline Age group & Class I n (\%) & Class II $n(\%)$ & Class III n (\%) & Class IV n (\%) & Total $n(\%)$ \\
\hline $15-20$ & 0 & 0 & $60(3)$ & $13(0.7)$ & $73(4)$ \\
\hline $21-30$ & $8(0.4)$ & $7(0.4)$ & 169 (10) & $30(2)$ & $214(12)$ \\
\hline $31-40$ & 25 (1) & 18 (1) & 323 (19) & $28(2)$ & $394(23)$ \\
\hline $41-50$ & $119(7)$ & 57 (3) & 309 (18) & $43(2)$ & $528(30)$ \\
\hline $51-60$ & $71(4)$ & $54(3)$ & $170(10)$ & $28(2)$ & 323 (19) \\
\hline $61-70$ & $74(4)$ & $46(3)$ & $50(3)$ & $15(0.8)$ & $185(11)$ \\
\hline $71-80$ & $11(0.6)$ & $6(0.3)$ & $6(0.3)$ & 0 & $23(1)$ \\
\hline \multicolumn{6}{|l|}{ Gender } \\
\hline Female & $148(9)$ & $99(6)$ & $513(29)$ & $65(4)$ & $825(47)$ \\
\hline Male & $160(9)$ & $89(5)$ & $574(33)$ & $92(5)$ & $915(53)$ \\
\hline
\end{tabular}

discussion, and comprehension of the indicated prosthetic treatment among dental colleagues, students and technicians, but also facilitates case history recording and simplifies information exchange between dentists and the auxiliary staff. 5,6 Kennedy's classification of partially edentulous arches is universally acceptable and that was followed in this study. Kennedy's classification was originally proposed by Edward Kennedy in 1925. Kennedy's classification permits immediate visualization of partially edentulous arches and allows early distinction between tooth supported and tooth tissue supported cases. The aim of this study was to determine the patterns of partial edentulism in patients who come to the Outpatient Department of Prosthodontics, GPRDCH, Kurnool, during the period of 18 months.

\section{MATERIALS AND METHODS}

This study was carried out at the OPD, Prosthodontics at GPRDCH, Kurnool, Andhra Pradesh 1420 cases of partial edentulism were received during 18 months period from April 2011 to September 2012. The study included patients from 15 to 80 years age group and all the patients were examined clinically. Kennedy's classification was followed to classify partial edentulism. Kennedy's classes I, II, III and IV were categorized according to age and gender of the patient and also in the maxillary and mandibular arches.

\section{RESULTS}

Of the 1,420 patients, 320 patients had partial edentulism in both arches and 1,100 patients had only in one arch, with a total number of 1,740 partially edentulous arches. As the Table 2 shows, in both maxillary and mandibular arches Kennedy's class III is more frequent pattern of partial edentulism (66\% in maxilla, 59\% in mandible) and class IV is least encountered pattern ( $9 \%$ both in maxilla and mandible). Kennedy's classes I, II, III and IV were more prevalent among men than women (Table 3) whereas class II is more frequent in women than men.

\section{DISCUSSION}

Removable partial prosthodontics is a versatile, cost effective and reversible treatment method for partially edentulous patients at any age. ${ }^{7}$ There are many factors affecting the prevalence of edentulism, such as education, occupation, personal economic situation, attitude toward dental care, and life style. Preventive strategies to decrease the burden of tooth loss are of great importance. It is highly suggested that population based studies to be conducted to investigate the epidemiology and risk factors of edentulism and tooth loss in India. It is also important to evaluate the effect of tooth loss on the quality of life. Some earlier studies have also shown significant gender differences in edentulism with more males becoming edentulous than females. ${ }^{8,9}$

The study done by Ziad NAL-Dwairi also shown that bounded saddles (class III Kennedy classification) were the most common pattern of edentulism in the different age groups, where as class IV anterior saddles were the least common pattern observed. ${ }^{10}$

In the present study, patients of age groups 15 to 80 were surveyed. It was seen that the number of partially edentulous males, 745(52\%) outnumbered the females 675 (48\%). Kennedy's class III is the most frequent type of partial edentulism (62\%) followed by class I (18\%), class II (11\%) and lastly class IV (9\%). It was also noted that partial edentulism was more frequent in maxilla when compared to mandible. Kennedy's class III is more frequent both in maxilla and mandible. This could be due to the fact that the first molar is the first permanent tooth to erupt into the oral cavity, having a higher caries percentage and a higher chance of the tooth being extracted. Of the various classes of 
partial edentulism patients with class IV situation got their teeth replaced which could be attributed to esthetic reasons. This was followed by class I and II; the main reason could be for masticatory purposes. However, persons with class III had the less percentage of replacement, which could be because they had an option of getting their teeth replaced with a fixed partial denture or an implant which might have been beyond their affordability.

\section{CONCLUSION}

The incidence of various classes of partial edentulism may not only be a reflection of the pattern of tooth loss but also patient's demands and affordability of alternative prosthodontic treatment. The following conclusions were drawn from this study.

- Kennedy's class III is the most common class of partial edentulism both in male and female population.

- Partial edentulism is more frequent in maxilla when compared to mandible.

- More number of male patients was reporting partial edentulism in all Kennedy's classes except class II. This could be due to more access to dental care for male population.

With the pouring in of patients as the time passes, further evaluation and need of the continuing dental services need to be researched according to the regional demands.
Teeth loss effects speech, mastication and esthetics. Prosthodontic replacement is usually required to restore these functions. The design of prosthodontic replacement depends upon the pattern of partial edentulism.

\section{REFERENCES}

1. McGarry TJ, Nimmo A, Skiba JF, Ahlstrom RH, Smith CR, Koumjian JH, Arbree NS. Classification system for partial edentulism. J Prosthodont 2002;11(3):181-193.

2. Harvey WL, Hoffman W Jr. Ten-year study of trends in removable prosthodontic service. J Prosthet Dent 1989;62(6):644-646.

3. Prabhu N, Kumar S, Sauza M. Partial edentulousness in a rural population based on Kennedy's classification: an epidemiological study. J Indian Prosthet Soc 2009;9:18-23.

4. Miller EL. Systems for classifying dentulous arches. J Prosthet Dent 1970;24(1):25-40.

5. Stratton RJ, Wiebelt FJ. An atlas of removable partial denture design. Chicago, Illinois: Quintessence Publishing Co. Inc; 1988.

6. Frantz WR. Variability in dentists designs of a removable maxillary partial denture. J Prosthet Dent 1973;29(21):172-182.

7. Sadig WM, Idowu AT. Removable partial denture design: a study of selected population in Saudi Arabia. J Contemp Dent Pract 2002;3(4):40-53.

8. Suominen-Taipale AL, Alanen P, Helenius H, Nordblad A, Uutela A. Edentulism among Finnish adults of working age, 1978-1997. Comm Dent Oral Epidemiol 1999;27(5):353-365.

9. Hoover JN, Mc Dermott RE. Edentulousness in patients attending a university dental clinic. J Can Dent Assoc 1989;55(2):139-140.

10. Al-Dwairi ZN. Partial edentulism and removable denture construction: a frequency study in Jordanians. Eur J Prosthodont Restor Dent 2006;14(1):13-17. 